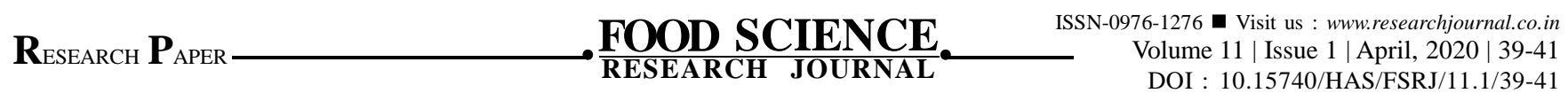

\title{
Infant feeding practices among tribal population
}

\author{
Binapani Deka, Ira Sarma and Tulika Borah
}

\begin{abstract}
Assam has a largely rural agrarian economy, which is characterized by high rate of work participation of women. The feeding practices, child rearing practices differs from community to community. The study has been carried out in two villages viz., Neulgaon and Laliti under Dhekargarah development block for study their existing infant feeding practices. The tribal population in the blocks is around 90 per cent and dominated by missing community. Their socio-cultural, economic and educational backgrounds differ from the other communities. A sizable portion of Deuri community also live in the area, although in different nearby villages. Women in this area are involved in various agricultural activities starting from sowing of seeds to hand weeding, harvesting and post-harvest activities. Their socio-cultural, economic and educational backgrounds differ from the other communities. Factors such as ignorance, illiteracy, lack of accessibility and inadequate utilization of health services contribute to poor health status of the tribes. Breastfeeding is an integral part of nurturing and nourishing process in new born health. Each tribe has its own exclusive practices in child rearing. The beliefs and practices related to feeding during the infancy period have a critical impact on the survival of child. In this context, a study has been carried out to identify the existing beliefs and practices on infant feeding among the tribal communities. Results showed that less knowledge about newborn feeding practices of the tribes exists in the study area. Harmful feeding practices due to misconceptions are still prevailing among the tribes despite advancement in health services. There is a need to assess the local tribe specific newborn rearing practices for promotion of beneficial practices and prevention of harmful practices.
\end{abstract}

Key Words : Infant feeding practices, Tribal population

How to cite this article : Deka, Binapani, Sarma, Ira and Borah, Tulika (2020). Infant feeding practices among tribal population. Food Sci. Res. J., 11(1): 39-41, DOI : 10.15740/HAS/FSRJ/11.1/39-41.Copyright@ 2020: Hind Agri-Horticultural Society.

Ira Sarma and Tulika Borah, Department of Human Development and Family Studies, College of Community Science, Assam Agricultural University, Jorhat (Assam) India 